CLINICAL STUDY

\title{
Evaluation of cardiac structure by echoreflectivity analysis in acromegaly: effects of treatment
}

M M Ciulla, P Epaminonda ${ }^{1,2}$, R Paliotti, M V Barelli, C Ronchi ${ }^{1}$, V Cappiello ${ }^{1}$, A Sartorio ${ }^{3}$, V Buonamici, F Magrini, P Beck-Peccoz ${ }^{1}$ and M Arosio ${ }^{1,2}$

Istituto di Medicina Cardiovascolare e Terapia Medica, Centro Interuniversitario di Fisiologia Clinica e Ipertensione, Milan, Italy, ${ }^{1}$ Istituto di Scienze Endocrine, Università di Milano, Ospedale Maggiore IRCCS, Milan, Italy, ${ }^{2}$ Unità di Endocrinologia Ospedale San Giuseppe-Fatebenefratelli (AFaR), Milan, Italy and ${ }^{3}$ Divisione Malattie Metaboliche III, Laboratorio Sperimentale di ricerche Endocrinologiche (LSRE), Istituto Auxologico Italiano, IRCCS, Milano e Piancavallo, Milan, Italy

(Correspondence should be addressed to Maura Arosio, U.O. Endocrinologia, Osp. S. Giuseppe, Via S. Vittore 12-20123 Milan, Italy; Email: maura.arosio@unimi.it)

\begin{abstract}
Objectives: Cardiac echoreflectivity is a noninvasive tool for evaluating cardiac fibrosis. The present paper aimed to study the modifications of cardiac echoreflectivity in a group of acromegalic patients before and after therapy, and to assess possible correlations with serum levels of procollagen III (PIIINP), a peripheral index of collagen synthesis.

Design and methods: Cardiac echoreflectivity (as assessed by analyzing 2-D echocardiograms digitized off-line onto a personal computer) and PIIINP levels were evaluated in 16 acromegalic patients of new diagnosis not affected by arterial hypertension (10 males, six females, age \pm S.D.: $38 \pm 10$ years), and in a group of 16 sex- and age-matched healthy subjects. All the patients were re-evaluated after surgical and/or medical therapy for acromegaly. The echo patterns were analyzed by software that supplies the derived collagen volume fraction (dCVF), an index of fibrosis.

Results: At baseline, acromegalic patients showed significantly higher dCVF values and PIIINP levels than healthy controls $(3.1 \pm 0.5 \%$ vs $1.6 \pm 0.3 \%, P<0.01$ and $8.7 \pm 2.2 \mathrm{vs} 3.1 \pm 1.1 \mathrm{ng} / \mathrm{ml}, P<0.05$, respectively, by unpaired Student's t-test). After therapy, dCVF and PIIINP levels normalized in the six controlled patients (that is, GH of $<2.5 \mu \mathrm{g} / \mathrm{l}$ and IGF-I within normal range) (dCVF from $2.8 \pm 0.4 \%$ to $1.4 \pm 0.2 \%, P<0.001$; PIIINP from $8 \pm 2.7$ to $3.3 \pm 1.9 \mathrm{ng} / \mathrm{ml}, P<0.05)$, while no significant changes were found in noncontrolled patients (dCVF from $3.3 \pm 0.6 \%$ to $2.9 \pm 1.2 \%$ and PIIINP from $9.1 \pm 1.9$ to $7.9 \pm 3.5 \mathrm{ng} / \mathrm{ml}, P=\mathrm{NS}$ ). A positive correlation between $\mathrm{dCVF}$ and PIIINP $(r=0.75, P<0.001)$ and between IGF-I and both dCVF and PIIINP $(r=0.65$ and 0.61 respectively, $P<0.05)$ was found in acromegalic patients.

Conclusions: Cardiac echoreflectivity, which may be a reflection of heart collagen content, is increased in patients with active acromegaly and correlates with PIIINP concentrations. After cure or adequate control of the disease, both parameters revert to normal. Echoreflectivity analysis could be a useful adjuvant parameter in the assessment of the activity of acromegalic disease.
\end{abstract}

European Journal of Endocrinology 151 179-186

\section{Introduction}

Acromegaly is characterized by a high incidence of cardiac complications, such as congestive heart failure and cardiac dysrhythmias $(1,2)$. Growth hormone $(\mathrm{GH})$ exerts its effects on heart tissue both directly and indirectly via insulin-like growth factor I (IGF-I). Both GH and IGF-I receptors are present in cardiac myocytes $(3,4)$, and local IGF-I expression has been shown in these cells (5). Over time, GH excess leads to a specific acromegalic cardiomyopathy, characterized by high prevalence of morphologic (biventricular hypertrophy, with dilation in the late stages) and histologic modifications (increase of heart collagen content, lymphomononuclear infiltration, myofibrillar degeneration and areas of monocyte necrosis) $(1,2$, $6-8)$. These alterations are worsened by possible coexistent hypertension $(9,10)$. Regression of cardiomyopathy has been observed after successful treatment of acromegaly with normalization of both GH and IGF-I levels $(11,12)$. In a previous paper (13), we studied the degree of cardiac structural alterations by analyzing the echo patterns by software which supplies an index of fibrosis, namely, the derived collagen volume fraction (dCVF). It has been shown that increased dCVF, reflecting the augmented myocardial echoreflectivity, is related to structural alterations involving interstitium, such as increased collagen deposition (14). 
Different kinds of collagen have been identified in humans; all of them are derived from longer precursor molecules named procollagens, which are synthesized intracellularly and secreted in extracellular space, where they are cleaved by aminoproteases before being released into the circulation $(15,16)$. Among the different molecules, type III procollagen is the precursor of the major component of interstitial fibrils, and it predominates in soft tissues such as myocardium (15). Since its aminoterminal peptide, aminoterminal propeptide of type III procollagen (PIIINP), is produced in equimolar proportions to collagen, serum measurements of this fragment can provide an index of collagen synthesis and turnover. PIIINP serum levels are related to growth rate in healthy children $(17,18)$ and closely mirror GH secretion, as they are low in both adult and childhood-onset GH deficiency $(19-21)$, are high in active acromegaly (22) and normalize after successful treatment $(23-25)$.

The present paper aimed to study the modifications of cardiac echoreflectivity in a group of acromegalic patients before and after therapy, and to assess possible correlations with serum levels of procollagen III (PIIINP), a peripheral index of collagen synthesis.

\section{Subjects and methods}

\section{Subjects}

Sixteen newly diagnosed euthyroid acromegalic patients (age: $38 \pm 10$ years; $\mathrm{M}: \mathrm{F}=10: 6, \mathrm{GH}: 23.1 \pm 23.6 \mu \mathrm{g} / \mathrm{l}$, IGF-1: $128 \pm 36 \mathrm{nmol} / \mathrm{l}$ ) without concomitant illness, such as arterial hypertension, ischemic heart disease, diabetes mellitus, chronic hepatic or respiratory diseases, were included in the study. The diagnosis was based on the presence of typical clinical acromegalic features, lack of suppression of serum GH concentration below $1 \mu \mathrm{g} / \mathrm{l}$ during a $75 \mathrm{~g}$ oral glucose tolerance test (OGTT), elevated serum IGF-I concentration for age and sex, and presence of a pituitary mass on magnetic resonance imaging. The duration of the disease before diagnosis was found to range from 1 to 8 years. A group of 16 age- and sex-matched healthy subjects recruited among either the hospital staff or acquaintances of patients were studied as controls. Informed consent was obtained from all participants in the study. The protocol was approved by the local ethical committee.

\section{Study protocol}

A detailed clinical history and physical examination was performed in each patient and control. Serum $\mathrm{GH}$ was evaluated as the mean of five samples collected during $2 \mathrm{~h}$ of saline infusion and IGF-I as the mean of two measurements made in two different days. Patients and controls underwent blood pressure measurement according to the WHO-International
Society of Hypertension Guidelines (1999), basal electrocardiogram, standard bidimensional echocardiography, ultrasonic tissue characterization and PIIINP serum levels assessment.

All the patients underwent surgical removal of the GH-secreting adenoma by the transnasosphenoidal approach. Ten patients were assessed after a median of 6 months after surgery alone and did not receive further treatment. Six patients were indeed evaluated after a median of 9 months of medical therapy (three on octreotide LAR $30 \mathrm{mg}$ i.m./28 days and three on lanreotide SR $60 \mathrm{mg}$ i.m./28 days). The patients were divided into two groups on the basis of the control of disease: acromegaly was considered controlled (C) when both mean GH of $<2.5 \mu \mathrm{g} / \mathrm{l}$ and normal IGF-I levels for age were achieved; otherwise it was considered not controlled (NC).

\section{Hormonal and PIIINP measurement}

Serum GH values were measured by a fluoroimmunoassay (Autodelfia hGH, Wallac Oy, Turku, Finland) with detectability level of $0.01 \mu \mathrm{g} / \mathrm{l}$ and intra- and interassay coefficients of variation of $2.1 \%$ and $2.9 \%$ respectively. Serum IGF-I concentrations were measured by a commercial RIA provided by Mediagnost (Tübingen, Germany), which allows the separation between IGFBP and IGF-I by acidification in IGF-II excess (sensitivity: $0.003 \mathrm{nmol} / \mathrm{l}$; intra- and interassay coefficients of variation of 3.2 and $8.9 \%$ respectively). Serum PIIINP levels were assessed by a commercial radioimmunoassay (Orion Diagnostics, Finland) - sensitivity: $2.6 \mu \mathrm{g} / \mathrm{l}$; intra-assay and interassay variation: $4.0 \%$ and $4.3 \%$ respectively.

\section{Echocardiographic studies}

Standard M-mode, two-dimensional and pulsed Doppler echocardiographic studies (Acuson 128XP; Acuson Inc., Mountain View, CA, USA) were performed in the left lateral recumbent position after a 10-min rest period, according to the recommendations of the American Society of Echocardiography (26). The recordings were made by the same investigator for both acromegalic patients and control subjects. In order to ensure more subject- and operator-independent results, the focus of the echo-beam was set and kept perpendicular to the midapex interventricular septum, allowing us to obtain the same angle of insonification in each patient.

The following measurements were recorded on Mmode tracing: left ventricular (LV) end-diastolic and end-systolic diameters, left atrial end-systolic diameter, interventricular septum thickness and posterior wall thickness. The relative thickness of the LV wall, with respect to the $L V$ end-diastolic diameter, was also calculated. The LV myocardial mass (LVM) was calculated from the M-mode measurements by 
the following formula:

$$
\begin{aligned}
\mathrm{LVM}= & 1.04 \times\left[(\mathrm{LVEDD}+\mathrm{LVPWT}+\mathrm{LVAWT})^{3}\right. \\
& \left.\left.-\mathrm{LVEDD}^{3}\right)\right]
\end{aligned}
$$

where 1.04 is a constant, LVEDD is the LV end diastolic diameter, LVPWT is the LV posterior wall thickness and LVAWT is the LV anterior wall thickness (27).

LV hypertrophy (LVH) was considered when LV myocardial mass values, corrected for body surface area (LVMI), were greater than or equal to $125 \mathrm{~g} / \mathrm{m}^{2}$ in males and females, according to Penn Convention sex-independent criteria.

The Doppler study provided indexes of left ventricular filling, which were derived from the mitral flow velocity curves: maximal early diastolic flow velocity $(\mathrm{E}, \mathrm{cm} / \mathrm{s})$, maximal late diastolic flow velocity $(\mathrm{A}, \mathrm{cm} / \mathrm{s})$ and $\mathrm{E} / \mathrm{A}$ ratio (normal value of $>1$ ). Finally, the ejection fraction $(\mathrm{EF} \%)$ was calculated as follows:

$$
(\mathrm{EDV}-\mathrm{ESV}) / \mathrm{EDV}
$$

where EDV and ESV are the diastolic and systolic LV volumes respectively.

\section{Ultrasonic tissue characterization (UTC)}

Echocardiographic images and simultaneous ECG tracings were recorded on videotape in S-VHS format. In each subject, two representative subsequent cardiac cycles (all patients had sinus rhythm at the surface electrocardiogram) were digitized off-line from the videotape onto a personal computer (Power Mackintosh G3 av; Apple Computer, Inc., Cupertino, CA, USA) for the subsequent echoreflectivity analysis, using the internal video digitizer card operating at 30 frames/s and 8 bits/pixel on a standard PAL pixel matrix $(640 \times 480$ pixels).

UTC was performed using two-dimensional, longaxis, end-diastolic, echo-recorded images. In each patient, the region of ventricular wall for the analysis was selected by positioning a square selection tool $(5 \times 5 \mathrm{~mm})$ in the mid-portion of interventricular septum, avoiding areas of echo dropout.

From each selection, according to a previously described procedure (14), a color-level histogram representing the frequency distribution (number of pixels versus echo intensity) was derived, using software developed in our laboratory. For each patient, we considered the average of three consecutive end-diastolic measurements. Histograms were described in terms of average pixel intensity and color-spectrum width (broadband $(\mathrm{Bb})$ ), which indicates the spread of the echoes about the mean distribution and reflects the interactions of echoes within the tissue, as a function of ultrasound velocity and distance between scatters. Collagen content (derived collagen volume fraction
(dCVF); normal values up to $2 \%)(13-14)$ was predicted as a dependent variable in a regression model, using the independent variable $\mathrm{Bb}$, which in a previous study has been proven to correlate with the histologically assessed collagen content $(13,14)$. In order to avoid the effects on image texture caused by the characteristics of the ultrasound image system, all values obtained in interventricular septum were normalized for blood echoreflectivity, which in each subject represents the upper reference point of the gray scale. Gain settings and gain compensation profiles were adjusted to obtain apparently uniform myocardial brightness throughout the echocardiogram in each subject, and no reject was used.

\section{Statistical analysis}

Data were analyzed with statistical software (SPSS-Rel 6.1.1; SPSS Inc., Chicago, IL, USA). Values obtained are reported as mean \pm standard deviation; the differences between groups were tested for significance by unpaired Student's $t$-test. Relationships between variables were assessed by Pearson's correlation test. $P$ values less than 0.05 were considered statistically significant.

\section{Results}

\section{Baseline}

Baseline characteristics of the acromegalic patients are summarized in the Table 1.

The derived collagen volume fraction was significantly higher in acromegalic patients than in controls (dCVF: $3.1 \pm 0.5 \%$ vs $1.6 \pm 0.3 \% ; P<0.0001$ ) (Fig. 1a).

Table 1 Baseline characteristics of acromegalic patients.

\begin{tabular}{lccccc}
\hline $\begin{array}{l}\text { Patient } \\
(\text { no. })\end{array}$ & $\begin{array}{c}\text { Age } \\
(\text { years })\end{array}$ & $\begin{array}{c}\text { GH } \\
(\mu \mathrm{g} / \mathrm{l})\end{array}$ & $\begin{array}{c}\text { IGF-I } \\
(\mathrm{nmol} / \mathrm{l})\end{array}$ & $\begin{array}{c}\text { dCVF } \\
(\%)\end{array}$ & $\begin{array}{c}\text { PIIINP } \\
(\mathrm{ng} / \mathrm{ml})\end{array}$ \\
\hline 1 & 38 & 3.6 & 86.3 & 2.28 & 6.5 \\
2 & 40 & 7.6 & 186 & 4.22 & 13.6 \\
3 & 50 & 11.9 & 124.7 & 3.33 & 8 \\
4 & 34 & 78.5 & 126.8 & 2.67 & 6.2 \\
5 & 51 & 11.1 & 176 & 3.25 & 12.4 \\
6 & 38 & 19.7 & 80 & 3.2 & 8.7 \\
7 & 37 & 15 & 143.8 & 2.94 & 7 \\
8 & 36 & 30.5 & 151.6 & 2.58 & 7.5 \\
9 & 51 & 18.6 & 92 & 2.5 & 7.6 \\
10 & 26 & 5.96 & 112.4 & 2.56 & 4.9 \\
11 & 38 & 20.9 & 149 & 3.38 & 9 \\
12 & 49 & 6.4 & 125 & 2.72 & 9.2 \\
13 & 22 & 71.4 & 125.5 & 3.42 & 9.2 \\
14 & 50 & 12.1 & 106.9 & 3.82 & 10.2 \\
15 & 31 & 4.2 & 75 & 3.2 & 10 \\
16 & 22 & 52.4 & 190.9 & 4.04 & 9.5 \\
Mean & $38 \pm 10$ & $23.1 \pm 23.6$ & $128 \pm 36$ & $3.1 \pm 0.5$ & $8.7 \pm 2.2$ \\
Controls & $42 \pm 7$ & - & - & $1.6 \pm 0.3$ & $3.1 \pm 1.1$ \\
\end{tabular}



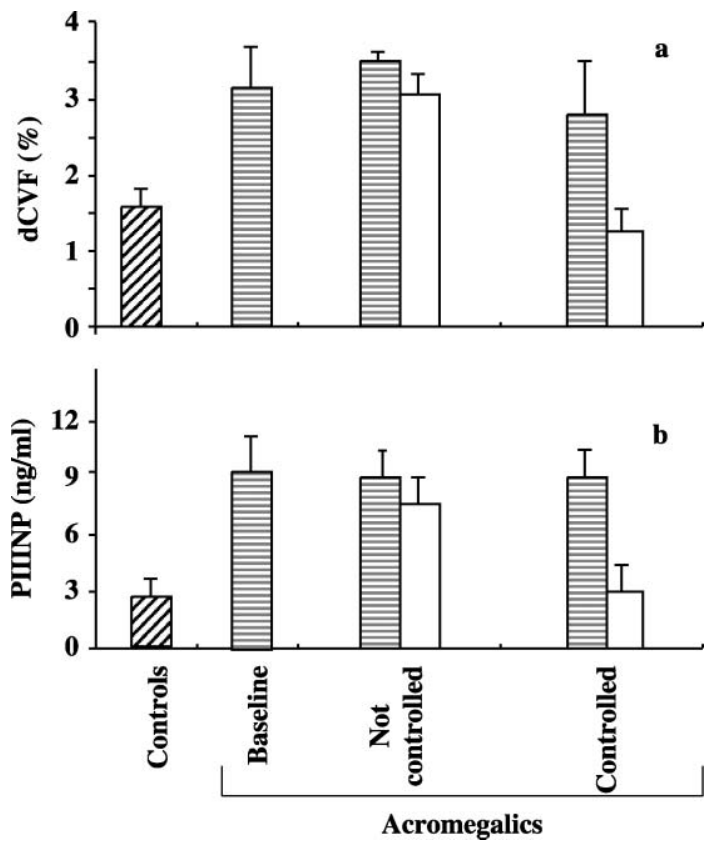

Figure 1 Modifications of dCVF\% values (panel a) and PIIINP serum concentrations (panel b) in 16 acromegalic patients before (目) and after ( $\square$ ) therapy and with respect to controls (四) (controlled acromegalics $=6$ patients, not controlled $=10$ patients)

As far as geometrical pattern is concerned, 14 patients $(88 \%)$ presented $\mathrm{LVH}$; in particular, six patients $(38 \%)$ had a concentric pattern, and the remaining eight $(50 \%)$ had eccentric LVH (Fig. 2). No patient showed either diastolic or systolic left ventricular dysfunction. Complete echocardiographic data are reported in Table 2 .

No correlations were found between biochemical and echographic parameters and between dCVF and LVMI.

Serum PIIINP levels were significantly higher in acromegalic patients than in controls $(8.7 \pm 2.2$ vs $3.1 \pm 1.1 \mu \mathrm{g} / \mathrm{l} ; P<0.0001$ ) (Fig. 1b).

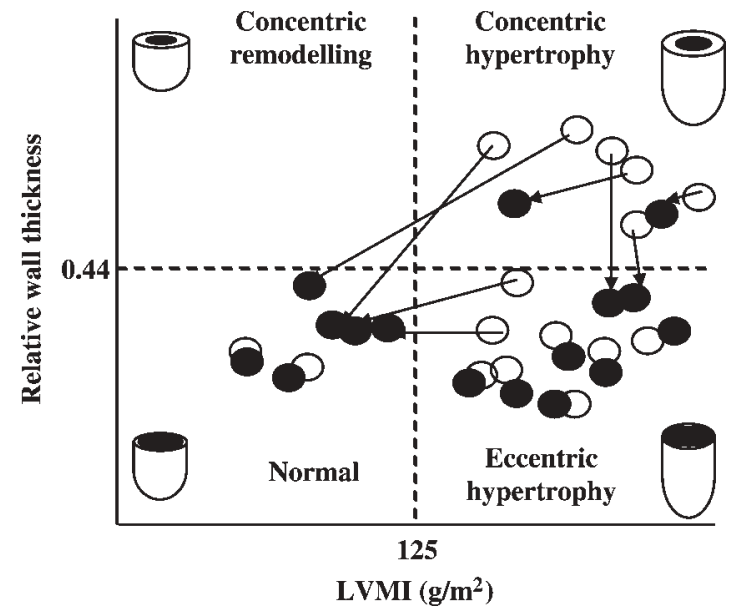

Figure 2 Changes in left ventricular geometry in acromegalic patients after therapy. Empty circles represent LVMI values before therapy, and full circles those after therapy.
In acromegalic patients, a significant correlation was found between dCVF and PIIINP $(r=0.75, P<0.001)$ (Fig. 3) and between dCVF and IGF-I serum concentrations $(r=0.65, P<0.05)$ (Fig. 4). In addition, IGF-I levels positively correlated also with PIIINP $(r=0.61, P<0.05)$.

\section{Effects of therapy}

Surgical removal was successful in five patients, and unsuccessful in 11. Among these 11 patients with persistent active disease, five were studied off medical therapy and six during therapy with long-acting somatostatin analogs, which obtained the normalization of $\mathrm{GH}$ and IGF-I levels in one further patient. Thus, six out of the 16 patients (five off and one on medical therapy) were classified as controlled (C), whereas 10 were classified as not controlled (NC). The two groups did not differ in GH, IGF-I, PIIINP and dCVF at baseline.

In all $\mathrm{C}$ patients, a reduction of LVM and LVMI (Table 2) and the movement of dCVF into the normal range $(1.43 \pm 0.22 \%, P=\mathrm{NS}$ vs controls) were observed (Fig. 5). In particular, the four patients with $\mathrm{LVH}$ at baseline, showed complete normalization of LVMI following normalization of the hormonal pattern (Fig. 2). In $C$ patients also, serum PIIINP levels fell to the normal range $(3.26 \pm 1.88 \mu \mathrm{g} / \mathrm{l}, P=\mathrm{NS}$ vs controls) (Fig. 1b). A positive correlation was found between the net decrease of IGF-I levels and both the net decreases of dCVF and of PIIINP serum concentrations $(r=0.66$ and 0.47 respectively, $P<0.01)$.

On the contrary, the NC patients showed persistence of increased dCVF $(2.91 \pm 1.22 \% ; P<0.001$ vs controls and $\mathrm{C}$ ), serum PIIINP concentrations $(7.88 \pm 3.53 \mu \mathrm{g} / \mathrm{l}$; $P<0.001$ vs controls and C) (Fig. 1) and LVH (LVMI $132.77 \pm 37.05 \mathrm{~g} / \mathrm{m}^{2} ; P<0.001$ vs controls and $\left.\mathrm{C}\right)$ (Fig. 2). Two NC patients presented normal dCVF values and other three normal PIIINP levels; these patients had serum IGF-I concentrations mildly elevated, with low GH levels. On the whole, after surgery, dCVF and IGF-I correlate well $(r=0.72$, $P<0.001)$.

\section{Discussion}

The present study aimed to verify to what extent the structural alterations observed in the myocardium of acromegalic patients are reversible after normalization of hormonal parameters. Few data (22-24) are available about the effects of medical or surgical treatments on collagen synthesis in acromegalic patients. Therefore, we evaluated myocardial echoreflectivity in a group of euthyroid and normotensive acromegalic patients before and after therapy. In a previous publication (13), we demonstrated the presence of increased cardiac echoreflectivity (estimated by dCVF) that was 
Table 2 Complete echocardiographic data of the 16 acromegalic patients.

\begin{tabular}{lcccc}
\hline & Before therapy & After therapy $(\mathrm{NC})$ & After therapy $(\mathrm{C})$ & $\boldsymbol{P}$ \\
\hline LVEDD $(\mathrm{mm})$ & $50.1 \pm 4.6$ & $51.7 \pm 6.0$ & $49.7 \pm 2.3$ & $\mathrm{NS}$ \\
LVESD $(\mathrm{mm})$ & $33.0 \pm 4.9$ & $34.3 \pm 8.9$ & $32.3 \pm 2.1$ & $\mathrm{NS}$ \\
LA $(\mathrm{mm})$ & $34.2 \pm 5.6$ & $33.4 \pm 3.6$ & $30.5 \pm 2.8$ & $\mathrm{NS}$ \\
IVS $(\mathrm{mm})$ & $10.1 \pm 1.7$ & $10.3 \pm 1.9$ & $8.7 \pm 1.5$ & $\mathrm{NS}$ \\
LVPWT $(\mathrm{mm})$ & $9.3 \pm 1.3$ & $9.2 \pm 1.6$ & $7.8 \pm 5.6$ & $\mathrm{NS}$ \\
RWT & $0.4 \pm 0.1$ & $0.4 \pm 0.04$ & $0.3 \pm 0.1$ & $\mathrm{NS}$ \\
LVM $(\mathrm{g})$ & $225.6 \pm 63.3$ & $244.6 \pm 103.1$ & $175.6 \pm 29.3$ & $P<0.05^{\star} P<0.01^{\circ}$ \\
LVMI $\left(\mathrm{g} / \mathrm{m}^{2}\right)$ & $12.8 \pm 25.1$ & $132.8 \pm 37.1$ & $94.0 \pm 7.5$ & $P<0.05^{\star} P_{0.01^{\circ}}$ \\
E/A $(\%)$ & $1.4 \pm 0.3$ & $1.3 \pm 0.2$ & $1.3 \pm 0.6$ & $\mathrm{NS}$ \\
EF $(\%)$ & $65 \pm 7$ & $64 \pm 9$ & $64 \pm 2$ & $\mathrm{NS}$ \\
\hline
\end{tabular}

LVEDD: left ventricular end-diastolic diameter; LVESD: left ventricular end-systolic diameter; LA: left atrial diameter; IVS: interventricular septum; LVPWT: left ventricular posterior wall thickness; RWT: relative wall thickness; LVM: left ventricular mass; LVMI: left ventricular mass index; E/A: transmitral E/A ratio; EF: ejection fraction, NC: not controlled acromegalic disease $(n=10)$, C: controlled acromegalic disease $(n=6)$.

* Before therapy vs not controlled.

${ }^{\circ}$ Controlled vs not controlled.

not related to the presence of arterial hypertension and well correlated with the duration of acromegaly. Beside acromegaly, myocardial echoreflectivity is raised in other diseases such as hypothyroidism (28) and arterial hypertension (14), pathologic conditions characterized by an increase of cardiac collagen matrix as in acromegaly. In fact, interstitial collagen deposition has an

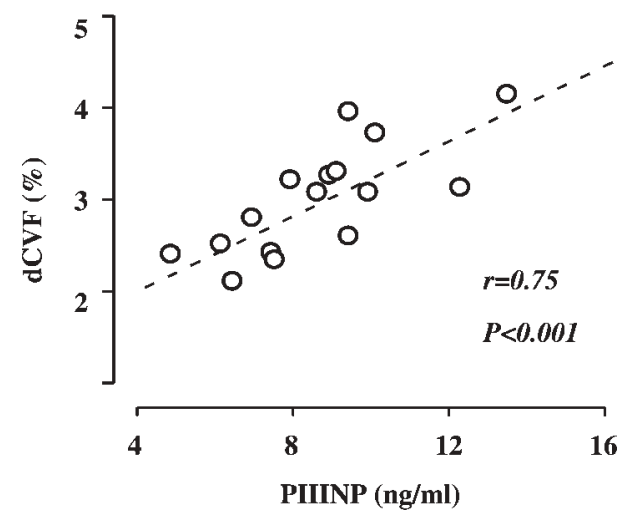

Figure 3 Correlation between dCVF and PIIINP serum concentrations in the 16 acromegalic patients before therapy.

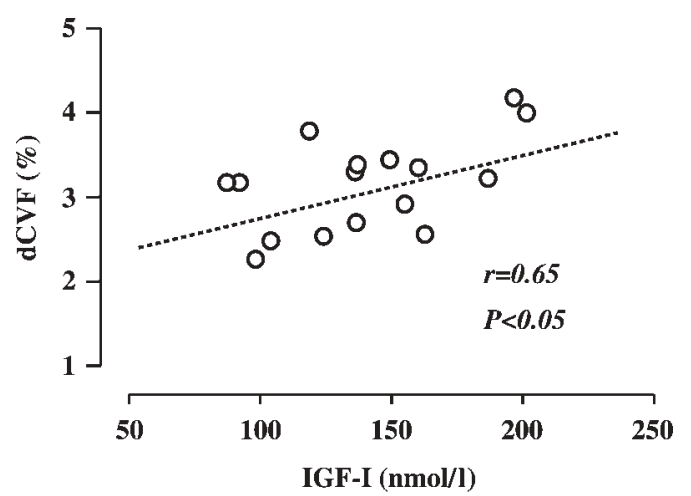

Figure 4 Correlation between dCVF and IGF-I serum concentrations in the 16 acromegalic patients before therapy. important influence on the echo texture image from the myocardium because of its marked acoustic impedance (29), and experimental and clinical studies have demonstrated a good correlation between the quantitative analysis of ultrasound signals and the degree of collagen accumulation (14). In the present study, the presence of increased myocardial echoreflectivity, which thus is probably a reflection of increased heart collagen content, is confirmed in all the euthyroid-normotensive acromegalic patients. In addition, it has been shown for the first time that dCVF reverted to normal after control of the disease, as a result of either surgery alone or surgery plus medical therapy. It is worth noting that the net dCVF decrease was well correlated with the net decrease of IGF-I levels. Among the 11 not controlled patients, two normalized dCVF values, though mild elevations in IGF-I levels, were present. However, both these patients had $\mathrm{GH}$ levels below $1 \mu \mathrm{g} / \mathrm{l}$. This observation may suggest that dCVF depends not only on circulating IGF-I concentrations but also on the absolute $\mathrm{GH}$ levels that could be involved in tissue IGF-I production and in intracardiac collagen turnover. In this respect, it is of interest that an IGF-I independent action of GH has been recently shown in vitro in cultured myocytes (30). Another peripheral marker of collagen metabolism is the amino-terminal propeptide of type III procollagen (PIIINP), which reflects soft-tissue collagen synthesis (the heart in particular). This marker has been used in children with GH deficiency (who have reduced PIIINP levels) as an early predictor of response to GH replacement therapy (19). The strict dependency of PIIINP on GH levels has been also confirmed in $\mathrm{GH}$ excess: in fact, in acromegaly, serum PIIINP levels are high and they decrease after therapy $(22-24)$. It is of interest that a positive correlation was found between PIIINP levels and dCVF, thus indicating that this index is a real marker of collagen content.

As far as geometric cardiac pattern is concerned, cardiac hypertrophy was present in the majority of 


\section{Baseline}

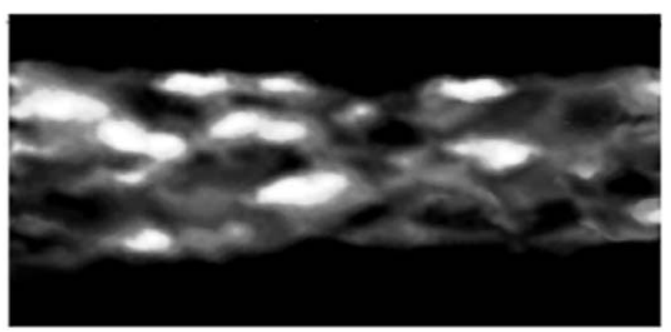

\section{After therapy}

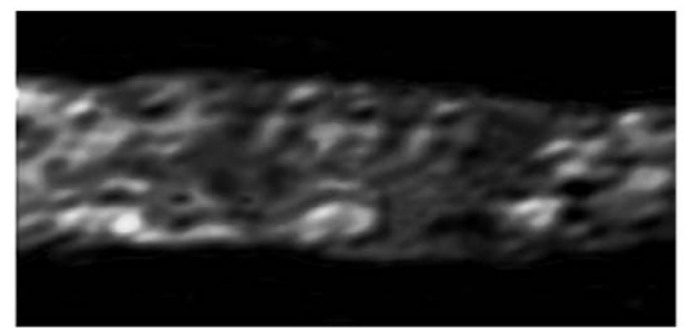

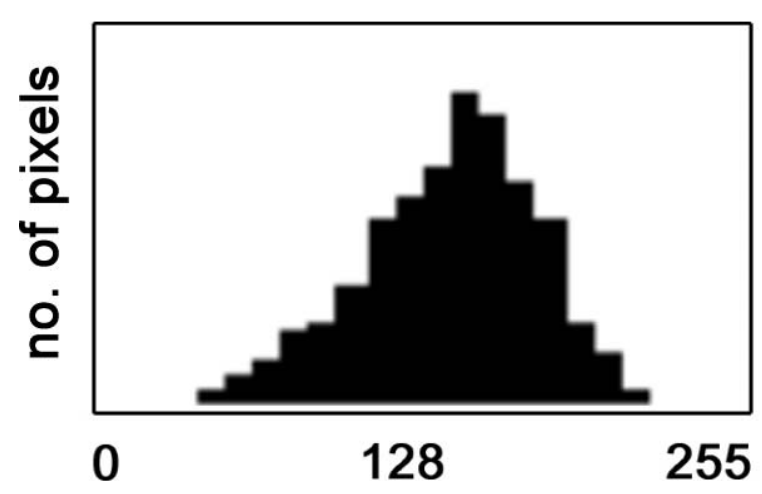
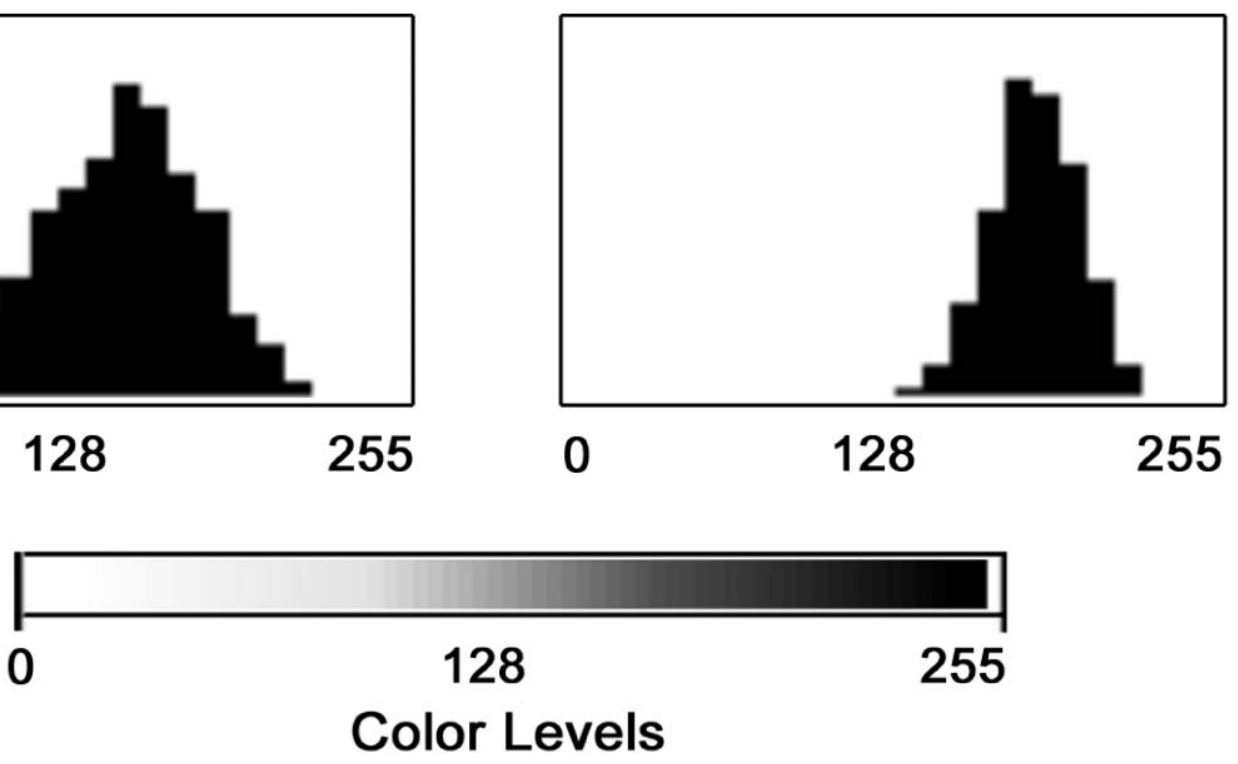

Figure 5 Upper panels: echocardiographic images of the interventricular septum in an acromegalic patient before (left) and after (right) treatment; in order to obtain a better visualization of myocardial structures, color scale was set at 256 colors $(0=y e l l o w$,

$128=$ magenta, $255=$ black) recoding the original 256 echo gray scale $(0=$ white, $255=$ black). Lower panels: schematic representation of the histograms obtained from the interventricular septum in the same patient. At baseline, the histogram is asymmetric and left-shifted, revealing increased echoreflectivity; the normalization of GH and IGF-I levels, after therapy, corresponds to a right shift of the histogram, which appears more symmetric and compact.

our untreated patients, as expected $(2,10,31)$. In agreement with several previous studies (10-12), left ventricular mass significantly decreased after therapy, without a significant correlation with dCVF. Collagen content is only one of the components of cardiac hypertrophy and seems to reflect the excessive stimulation by GH/IGF-I and the activity of acromegalic disease better than ventricular mass. Further studies will be necessary to determine whether dCVF correlates with other cardiac geometric parameters (such as wall thickness) and mainly with cardiac function.

As previously observed in a group of acromegalic patients (13), the increase in collagen deposition in the studied population, as estimated by dCVF, was not associated with diastolic dysfunction. Our observation could in part be explained by the low prevalence of arterial hypertension in the studied population, in agreement with the findings of another study (9).
In fact, the observed dCVF values, even if significantly higher than the normal ones, are lower than values observed in patients with a long-standing history of arterial hypertension and higher degrees of LV hypertrophy (14); this fact probably means that diastolic dysfunction, as indicated by the reduction of $\mathrm{E} / \mathrm{A}$ ratio, determines when the collagen deposition reaches 'critical' values. From a methodological point of view, it is also possible that other techniques not supported by our echo-machine, such as Doppler tissue imaging (DTI), or more invasive and expensive methods, such as radionuclide angiography (11), would have disclosed subtle alterations in diastolic function not detected by our method. However, up to now, the E/A ratio has been the most used index to evaluate the LV diastolic function in clinical settings.

In conclusion, our study showed that heart collagen content estimated by echoreflectivity levels is increased 
during uncontrolled acromegaly and correlates with PIIINP concentrations. After cure or adequate control of the disease, both parameters revert to normal. The identification of peripheral parameters of $\mathrm{GH}$ activity is important in the evaluation of acromegalic disease in order to find a better definition of cure and biologic control. In this respect, cardiac echoreflectivity and PIIINP may be considered simple, noninvasive and inexpensive tools to evaluate indirectly and follow up acromegalic cardiomyopathy.

\section{Acknowledgements}

We thank Dr Eva Palmieri for the PIIINP measurement. This work was supported in part by a research grant from FIRST funds of the University of Milan and from Progetti di Ricerca Corrente, Istituto Auxologico Italiano, IRCCS, Milan, Italy.

\section{References}

1 Fazio S, Cittadini A, Sabatini D, Merola B, Colao AM, Biondi B et al. Evidence for biventricular involvement in acromegaly: a doppler echocardiography study. European Heart Journal $1993 \mathbf{1 4}$ 26-33.

2 Saccà L, Cittadini A \& Fazio S. Growth hormone and the heart. Endocrine Review 199415 555-573.

3 Mathews LS, Enmberg B \& Norstedt G. Regulation of rat growth hormone receptor gene expression. Journal of Biological Chemistry $1989179905-9910$.

4 Guse AH, Kiess W, Funk B, Kessler U, Berg I \& Gercken G. Identification and characterization of insulin like growth factor receptors on adult rat myocytes: linkage to inositol1.4.5-triphosphate formation. Endocrinology $1992 \quad \mathbf{1 3 0}$ 145-151.

5 Isaksson OGP, Eden S \& Jansson JO. Mode of action of pituitary growth hormone on target cells. Annual Review of Physiology $198547483-499$.

6 Frustaci A, Chimenti C, Setoguchi M, Guerra S, Corsello S, Crea F et al. Cell death in acromegalic cardiomyopathy. Circulation 1999 99 1426-1434.

7 Lie JT \& Grossman SJ. Pathology of the heart in acromegaly: anatomic findings in 27 autopsied patients. American Heart Journal $198010041-51$.

8 Melmed S. Acromegaly. New England Journal of Medicine 1990 322 966-977.

9 Lopéz-Velasco R, Escobar-Morreale HF, Vega B, Villa E, Sancho JM, Moya-Mur JL et al. Cardiac involvement in acromegaly: specific myocardiopathy or consequence of systemic hypertension? Journal of Clinical Endocrinology and Metabolism $1997 \mathbf{8 2}$ 1047-1053

10 Colao AM, Marzullo P, Di Somma C \& Lombardi G. Growth hormone and the heart. Clinical Endocrinology $2001 \mathbf{5 4}$ $137-154$.

11 Colao A, Cuocolo A, Marzullo P, Nicolai E, Ferone D, Della Morte $\mathrm{AM}$ et al. Is the acromegalic cardiomyopathy reversible? Effect of 5 year normalization of growth hormone and insulin like growth factor I levels on cardiac performance. Journal of Clinical Endocrinology and Metabolism 200186 1551-1557.

12 Theusen L, Christensen SE, Weeke J, Orskov H \& Henningsen P. The cardiovascular effects of octreotide treatment in acromegaly: an echocardiographic study. Clinical Endocrinology 198930 $619-625$.
13 Ciulla M, Arosio M, Barelli MV, Paliotti R, Porretti S \& Valentini P. Blood pressure-independent cardiac hypertrophy in acromegalic patients. Journal of Hypertension 199917 1965-1969.

14 Ciulla M, Paliotti R, Hess DB, Tjahja E, Campbell SE, Magrini F et al. Echocardiographic patterns of myocardial fibrosis in hypertensive patients: endomyocardial biopsy versus ultrasonic tissue characterization. Journal of American Society of Echocardiography $199710657-664$.

15 Prockop DJ, Kivirikko KI, Tuderman L \& Guzman NA. The biosynthesis of collagen and its disorders. New England Journal of Medicine $197930177-85$.

16 Fessler JH \& Fessler LI. Biosynthesis of procollagen. Annual Review of Biochemistry $1978 \mathbf{4 7} 129$.

17 Danne T, Gruters A, Schuppan D, Quantas N, Enders I \& Weber B. Relationship of procollagen type III propeptide-related antigens in serum to somatic growth in healthy children and patients with growth disorders. Journal of Pediatrics 1989114 257-260.

18 Risteli J, Niemi S, Trivedi P, Maentausta O, Mowat AP \& Risteli L. Rapid equilibrium radioimmunoassay for the amino terminal propeptide of type III procollagen. Clinical Chemistry $1988 \mathbf{3 4}$ $715-718$.

19 Tapaneinen P, Risteli L, Knip M, Kaar M-L \& Risteli J. Serum aminoterminal propeptide of type III procollagen: a potential predictor of the response to growth hormone therapy. Journal of Clinical Endocrinology and Metabolism $1989 \quad 67$ 1244-1249.

20 Sartorio A, Arosio M, Conti A, Ferrero S, Porretti S \& Faglia G. Long term monitoring of rec-GH treatment by serial determination of serum aminoterminal propeptide of type III procollagen in children and adults with GH deficiency. Journal of Endocrinological Investigation 199922 169-175.

21 Bollerslev J, Møller J, Thomas S, Djøseland O \& Christiansen JS. Dose-dependent effects of recombinant human growth hormone on biochemical markers of bone and collagen metabolism in adult growth hormone deficiency. European Journal of Endocrinology $1996135666-671$.

22 Verde G, Santi I, Chiodini P, Cozzi R, Dallabonzana D, Oppizzi G et al. Serum type III procollagen propeptide levels in acromegalic patients. Journal of Clinical Endocrinology and Metabolism $1986 \mathbf{6 3}$ 1406-1410.

23 Salmela PI, Juustila H, Pyhtinen J, Jokinen K, Alavaikko M \& Ruokonene A. Effective clinical response to long term octreotide treatment, with reduced serum concentrations of growth hormone, insulin-like growth factor-I, and the amino-terminal propeptide of type III procollagen in acromegaly. Journal of Clinical Endocrinology and Metabolism 1990 70 1193-1201.

24 Piovesan A, Terzolo M, Reimondo G, Pia A, Codegone A, Osella G et al. Biochemical markers of bone and collagen turnover in acromegaly or Cushing syndrome. Hormone and Metabolic Research $199426234-237$.

25 Sartorio A, Monzani M, Conti A, Casati G \& Faglia G. Serum amino-terminal propeptide of type III procollagen (PIIINP) levels in patients with acromegaly before and after pituitary adenomectomy. European Journal of Internal Medicine $1993 \mathbf{4}$ 79-83.

26 Sahn DJ, De Maria A, Kisslo J \& Weyman A. The committee on M-mode standardization of the American Society of Echocardiography. Recommendations regarding quantification in M-mode echocardiography: results of a survey of echocardiographic measurements. Circulation 197858 1072-1083.

27 Deveraux RB. Detection of left ventricular hypertrophy by Mmode echocardiography. Anatomic validation, standardization and comparison to other methods. Hypertension 19879 II $19-26$.

28 Ciulla M, Paliotti R, Cortelazzi D, Tortora G, Barelli MV, Buonamici $V$ et al. Effects of thyroid hormones on cardiac structure: a tissue characterization study in patients with thyroid disorders before and after treatment. Thyroid 20017 613-619. 
29 Kossoff G, Grossett WJ, Carpenter DA, Jellins J \& Dadd MJ. Principles and classification of soft tissues by grey scale echography. Ultrasound in Medicine and Biology 1976 2 89-105.

30 Clayton RN. Cardiovascular function in acromegaly. Endocrine Reviews $200324272-277$.

31 Lombardi G, Colao A, Marzullo P, Biondi B, Palmieri E \& Fazio S. the Multicenter Italian Study Group on Lanreotide. Improvement of left ventricular hypertrophy and arrhythmias after lanreotide-induced
GH and IGF-I decrease in acromegaly. A prospective multicenter study. Journal of Endocrinological Investigation 200225 971-976.

Received 19 December 2003

Accepted 14 April 2004 